\title{
Phospholipase C Beta 1: a Candidate Signature Gene for Proneural Subtype High-Grade Glioma
}

\author{
Guangrong $\mathrm{Lu}^{1} \cdot$ Jeffrey T. Chang ${ }^{2} \cdot{\text { Zheyu } \mathrm{Liu}^{3}}^{3}$ \\ Yong Chen ${ }^{3,4} \cdot$ Min $\mathrm{Li}^{1,2,5}$ - Jay-Jiguang Zhu ${ }^{1}$
}

Received: 13 July 2015 / Accepted: 28 October 2015 / Published online: 28 November 2015

(C) The Author(s) 2015. This article is published with open access at Springerlink.com

\begin{abstract}
Phospholipase C beta 1 (PLC $\beta 1$ ) expresses in gliomas and cultured glial cells, but its expression is barely detectable in normal glial cells. We analyzed data from Gene Expression Omnibus (GEO-GDSxxx), The Cancer Genome Atlas (TCGA), and the Repository for Molecular Brain Neoplasia Data (REMBRANDT) to explore the potential role of PLC $\beta 1$ as a biomarker in high-grade glioma (HGG). PLC $\beta 1$ expression is significantly higher in grade III gliomas than that in grade IV gliomas from GDS1815 ( $n=24$ vs. 76 ), GDS1962 ( $n=19$ vs. 81 ), and GDS1975 ( $n=26$ vs. 59 ). In GDS1815, PLC $\beta 1$ expression correlates with several known proneural $(\mathrm{PN})$ signature genes; its expression from PN
\end{abstract}

Electronic supplementary material The online version of this article (doi:10.1007/s12035-015-9518-2) contains supplementary material, which is available to authorized users.

Jay-Jiguang Zhu

jay.jiguang.zhu@uth.tmc.edu

1 The Vivian L. Smith Department of Neurosurgery, The University of Texas Health Science Center at Houston (UTHealth) Medical School, 6400 Fannin Street, Suite 2800, Houston, TX 77030, USA

2 The Department of Integrative Biology and Pharmacology, The University of Texas Health Science Center at Houston (UTHealth) Medical School, Houston, TX 77030, USA

3 Division of Biostatistics, UTHealth School of Public Health, Houston, TX 77030, USA

4 Present address: Department of Biostatistics and Epidemiology, Center for Clinical Epidemiology and Biostatistics, Perelman School of Medicine, University of Pennsylvania, Philadelphia, PA 19104, USA

5 Present address: Department of Medicine and Department of Surgery, The University of Oklahoma Health Sciences Center, Oklahoma City, OK 73104, USA subtype $(n=15)$ is significantly higher than that from mesenchymal (Mes) subtype ( $n=33)$ HGG. In GDS1962, PLC $\beta 1$ expression is the highest in nontumor brain tissue $(n=23)$ and is significantly higher than its expression in grade II gliomas [astrocytomas $(n=7)$ and oligodendrogliomas $(n=37)$ ]. A Kaplan-Meier survival curve from a REMBRANDT cohort demonstrates that glioma patients with intermediate PLC $\beta 1$ expression $(n=103)$ survived significantly longer than PLC $\beta 1$ downregulated $(2 \mathrm{X})$ groups $(n=226)$. From TCGA data, PLC $\beta 1$ RNA-Seq signal inversely correlates with the pathological grades, and PLC $\beta 1$ expression in PN $(n=8)$ is of significantly higher levels than that in Mes $(n=8)$ subtypes of glioblastoma. The top $50 \%$ of PLC $\beta 1$ expression subgroup $(n=294)$ of gliomas (grades II to IV merged) survived significantly longer than the low 50 percentile of the PLC $\beta 1$ expression subgroup ( $n=293$ ). $p$ values are less than 0.05 for all these analyses. We conclude that PLC $\beta 1$ is a candidate signature gene for PN subtype HGG, and its expression inversely correlates with glioma pathological grade and is a potential prognostic factor.

Keywords PLC $\beta 1$. Glioma · Glioblastoma · Proneural · Signature gene $\cdot$ Biomarker $\cdot$ REMBRANDT $\cdot$ TCGA

\section{Introduction}

Gliomas are the most common primary brain tumors, and the pathologic grade is the most important factor determining patients' prognosis $[1,2]$. Originally established by the World Health Organization (WHO) in 1993 and then updated in 2007, the four-tiered grading system for glioma outlines grade I as the least aggressive and grade IV as the most aggressive type of gliomas [3]. Grades I/II and III/IV are also collectively referred to as low- (LGG) and high-grade gliomas (HGG), 
respectively. Grade IV gliomas, also known as glioblastoma multiforme (GBM), are the most common and the most malignant type of primary brain tumor and account for 50-60\% of all gliomas [4]. Patients can develop gliomas at any age; however, LGGs are more often found in children and young adults and HGGs are more prevalent in the elderly. Other known prognostic factors include patient's age at initial diagnosis, extent of tumor resection, and Karnofsky performance score $[1,5]$.

With advancement of molecular biology technology, new methods for classifying gliomas have emerged in recent years [6]. The early established methods include gene mutation analysis and genome-wide screening, which permit identification of single or multiple gene abnormalities, epigenetic changes, and/or chromosomal anomalies [7-9]. The latest developments, including gene expression profiling, microarray technique, and whole genome sequencing, are capable of studying tens of thousands of genes simultaneously. Previous studies have identified groups of genes being upor downregulated within different subtypes of gliomas. Some gene expression patterns are associated with patient survival rates [6]. As a result, a new concept of "signature" genes has been introduced to classify HGG based on global gene transcripts differences [10-12]. For example, two studies subclassified HGG into three (Mes, PN, and proliferative) and four (Mes, PN, neuronal, and classical) subtypes, respectively $[10,11]$. Two different sets of signature genes for PN subtypes were used to separate the PN subtype from the other subtypes: set 1 of the signature genes for PN subtypes comprised OLIG2, MAP2, DCX, NeuN, ERBB4, GAD2, etc. and set 2 consisted of OLIG2, ERBB3, SOX2, NKX2-2, DLL3, etc. $[10,11]$. CHI3L1/YKL-40 is used as Mes subtype signature gene by both studies $[10,11]$. Other Mes signature genes include HLA-G, SERPINE1, CA12, etc. [11]. Strikingly, the expression of signature genes for PN and Mes subtypes appears to be mutually exclusive. It is observed that during GBM progression or recurrence, a unidirectional subclass shift occurs from PN toward Mes subtype, which represents a possible common pattern of disease progression [11]. Patients with PN subtype GBM survive longer on average than those afflicted with other subtypes despite the fact that PN subtype glioblastoma patients do not benefit significantly from temozolomide and radiotherapy [10, 11]. Although studies attempting to classify GBM subtypes do not always use the same set of signature genes, classification of PN and Mes subtypes is concordant in almost all related studies [10, 11, 13]. Therefore, it is desirable to identify biomarkers that allow quick and accurate identification of PN from other subtypes.

The phospholipase $\mathrm{C}$ beta 1 (PLC $\beta 1$ ) gene is mapped to human chromosome 20p12. It is expressed predominantly in neurons of the central nervous system and is barely detectable in other tissues or cell types [14-17]. The PLC $\beta 1$ protein catalyzes the formation of inositol 1,4,5-trisphosphate and diacylglycerol from phosphatidylinositol 4,5-bisphosphate (PIP2), which plays an important role in the intracellular signal transduction of extracellular signals, such as metabotropic glutamate. In rodent brain tissue, PLC $\beta 1$ is present in pyramidal neurons and interneurons, but is absent in astrocytes by immunohistochemistry $[15,18,19]$. However, PLC $\beta 1$ expression is detectable in cultured oligodendrocytes and astrocytes $[20,21]$. In addition, PLC $\beta 1$, while absent in freshly isolated normal glial cells, has been detected in C6 rat glioma cell lines [21-23].

We hypothesize that PLC $\beta 1$ could be a signature gene in glioma subclassification given its absence in normal glial cells, yet presence in glioma specimens. In addition, PLC $\beta 1$ expression is inducible in primary cultured glial cells [21,22].

Microarray and RNA Sequencing (RNA-Seq) data, including that measuring PLC $\beta 1$ expression, was submitted to the NIH-maintained Gene Expression Omnibus (GEO) and The Cancer Genome Atlas (TCGA) database [11, 12, 24]. In addition, GEO dataset-GDS1815, the Repository for Molecular Brain Neoplasia Data (REMBRANDT, https://caintegrator. nci.nih.gov/rembrandt), and TCGA databases provide patient survival information along with PLC $\beta 1$ microarray/ RNA-Seq data, both of which allow investigators to perform survival analysis based on different PLC $\beta 1$ expression levels. In this study, we retrieved data and performed analyses to determine (1) if PLC $\beta 1$ is a candidate signature gene for the PN subtype glioma, (2) the potential correlation between its expression and glioma's pathological grades, and (3) its prognostic value in glioma patients.

\section{Materials and Methods}

\section{Ethics Statement}

The usage of data and images from the NIH- and TCGAmaintained databases and from the Human Protein Atlas (HPA, http://www.proteinatlas.org) in this study meets the data use policies set by NIH, TCGA, and HPA, respectively.

\section{Access to Online Public Databases}

For this study, we used online public databases containing PLC $\beta 1$ microarray and RNA-Seq data, survival data, and immunohistochemistry (IHC) results. Microarray data is accessible from NIH-maintained website GEO, which serves as a public repository for a wide range of high-throughput experimental data. These datasets include single and dual channel microarray-based experiments measuring messenger RNA (mRNA) data. GEO staffs have selectively curated GEO series into a more compact format, GEO dataset (GDSxxxx), which includes a single spreadsheet of "final" values and accompanying rich sample annotation. Original microarray data 
Table 1 Microarray data retrieved from NIH-maintained GEO databases in this study

\begin{tabular}{|c|c|c|c|c|}
\hline Database & Contributor & Samples & Probes & Link \\
\hline \multirow[t]{5}{*}{ GDS1815 [11, 25] } & \multirow[t]{5}{*}{$\begin{array}{l}\text { Genentech, Inc., South } \\
\text { San Francisco, CA, USA }\end{array}$} & \multirow{5}{*}{$\begin{array}{l}100 \text { cases } \\
\text { Grade III and IV high-grade } \\
\text { gliomas; primary and } \\
\text { recurrent tumors }\end{array}$} & PLC $\beta 1-1$ & $\begin{array}{l}\text { http://www.ncbi.nlm.nih.gov/geo/tools/ } \\
\text { profileGraph.cgi?ID=GDS1815:213222_at }\end{array}$ \\
\hline & & & PLC $\beta 1-2$ & $\begin{array}{l}\text { http://www.ncbi.nlm.nih.gov/geo/tools/ } \\
\text { profileGraph.cgi?ID=GDS1815:215687_x_at }\end{array}$ \\
\hline & & & PLC $\beta 1-3$ & $\begin{array}{l}\text { http://www.ncbi.nlm.nih.gov/geo/tools/ } \\
\text { profileGraph.cgi?ID=GDS1815:211925_s_at }\end{array}$ \\
\hline & & & OLIG2 & $\begin{array}{l}\text { http://www.ncbi.nlm.nih.gov/geo/tools/ } \\
\text { profileGraph.cgi?ID=GDS1815:213825_at }\end{array}$ \\
\hline & & & ERBB4 & $\begin{array}{l}\text { http://www.ncbi.nlm.nih.gov/geo/tools/ } \\
\text { profileGraph.cgi?ID=GDS1815:214053_at }\end{array}$ \\
\hline \multirow[t]{3}{*}{ GDS2853 [27] } & \multirow{3}{*}{$\begin{array}{l}\text { Children's National Medical } \\
\text { Center, Washington, DC, } \\
\text { USA }\end{array}$} & \multirow{3}{*}{$\begin{array}{l}14 \text { cases } \\
\text { Low- vs. high-grade } \\
\text { astrocytomas }\end{array}$} & PLC $\beta 1$ & $\begin{array}{l}\text { http://www.ncbi.nlm.nih.gov/geo/tools/ } \\
\text { profileGraph.cgi?ID=GDS2853:35980_at }\end{array}$ \\
\hline & & & OLIG2 & $\begin{array}{l}\text { http://www.ncbi.nlm.nih.gov/geo/tools/ } \\
\text { profileGraph.cgi?ID=GDS2853:40624_at }\end{array}$ \\
\hline & & & ERBB4 & $\begin{array}{l}\text { http://www.ncbi.nlm.nih.gov/geo/tools/ } \\
\text { profileGraph.cgi?ID=GDS2853:37273_at }\end{array}$ \\
\hline GDS1962 [26] & $\begin{array}{l}\text { National Cancer Institute, } \\
\text { Bethesda, MD, USA }\end{array}$ & $\begin{array}{l}180 \text { cases } \\
\text { Nontumors, astrocytoma } \\
\quad \text { (grades II, III, IV), } \\
\text { oligodendroglioma } \\
\text { (grades II and III) }\end{array}$ & PLC $\beta 1$ & $\begin{array}{l}\text { http://www.ncbi.nlm.nih.gov/geo/tools/ } \\
\text { profileGraph.cgi?ID=GDS1962:213222_at }\end{array}$ \\
\hline GDS1975 [12] & $\begin{array}{l}\text { Translational Genomics, } \\
\text { Phoenix, AZ, USA }\end{array}$ & $\begin{array}{l}85 \text { cases } \\
\text { Astrocytomas, mixed } \\
\text { oligoastrocytoma, } \\
\text { oligodendroglioma, } \\
\text { and GBM }\end{array}$ & PLC $\beta 1$ & $\begin{array}{l}\text { http://www.ncbi.nlm.nih.gov/geo/tools/ } \\
\text { profileGraph.cgi?ID=GDS1975:213222_at }\end{array}$ \\
\hline
\end{tabular}

can be accessed through links provided in Table 1. Three PLC $\beta 1$ probes (213222_at; 215687 __at; $211925 \_$s_at) are used in datasets of GDS1815, GDS1962, and GDS1975, which studied 100,180 , and 85 cases, respectively [11, 12, 25, 26]. GDS2853 dataset used a different probe, 35980_at PLC $\beta 1$ [27].

We also acquired LGG and HGG data (RSEM-normalized RNA-Seq data) from the Broad Firehose database released on December 6, 2014 by TCGA. Data from glioma grades II to IV was merged for analyzing PLC $\beta 1$ gene expression; batch effects were removed by using the distance-weighted discrimination (DWD) method [28]. From the clinical annotations, we extracted the pathological grades, patient survival status, and censored data. Glioblastoma subtypes (PN, Mes, classic, and neuronal or proliferative) were previously determined in other studies [10].

The REMBRANDT database is in the public domain and open for researchers. The REMBRANDT website provides different modes to extract raw data for analysis. These selections are glioma and its subcategories consisting of astrocytoma, oligodendrogliomas, and GBM. This study focuses on glioma and its subclass astrocytoma since glioma and astrocytoma data contain samples from three (II, III, and IV) pathological grades, and they are large sample sizes for analysis. Oligodendrogliomas and GBM only have two (II and III) and one (IV) grades, respectively, and their sample sizes are relatively small for analysis. The default setting for Kaplan-Meier survival plot is based on stratified groups of genes upregulated $\geq 2$.0-folds, downregulated $\geq 2$.0-folds, and at the intermediate level; reporter type is Affymerix. For a survival plot based on PLC $\beta 1$ gene expression, the default setting selects data generated from the 213222 at probe because its data has the highest geometric mean intensity. (Note: The REMBRANDT data portal has been migrated to the Georgetown Database of Cancer, a knowledge discovery platform which supports access of the data by the scientific community.)

Human Protein Atlas is a website that enables systematic analysis of the human proteome using antibody-based proteomics and provides images for IHC results in human tissues. This website permits the utilization and publication of its data as outlined in its Data Usage Policy ("the publication and/or presentation are solely for informational and non-commercial purposes" and "the source of the data and/or image is referred to this site and/or one or more of our publications are cited.")

\section{Antibody Used in IHC}

Based on the information on the HPA website, glioma tissue was stained with four different PLC $\beta 1$ antibodies [HPA034743 
and HPA057910 (Sigma-Aldrich, St. Louis, MO); CAB004275 and CAB005334 (Santa Cruz Biotechnology, Dallas, TX)]. Patient samples were all deidentified and subjects are listed by ID, gender, age, and pathological grade.

\section{Statistical Analysis}

All data is presented as mean values \pm standard error of the mean (SEM) in the histograms. Distribution of expression level was examined by quantile-quantile plot (Q-Q plot) to compare with normal distribution. Statistical association was measured by Pearson correlation embedded in Microsoft Excel. GraphPad Prism (version 6.0; GraphPad Software, San Diego, CA, USA) was used to generate both a bar graph histogram and a Kaplan-Meier survival plot. We compared the expression level of PLC $\beta 1$ across grades or subtypes with a twotailed $t$ test; the log-rank test was used for the Kaplan-Meier survival plot. A difference was considered to be statistically significant if the $p$ value was less than 0.05 (i.e., $p<0.05$ ) [29].

\section{Results}

\section{PLC $\beta 1$ Expression Correlates with Other Known PN Subtype Signature Genes in GDS1815}

The GDS1815 dataset contains microarray data generated from 22,283 gene probes in 100 high-grade glioma samples. Three probes (213222_at; 215687_x_at; 211925_s_at) were used to detect PLC $\beta 1$ transcripts. Microarray data, presenting as signal strengths generated by probe 213222 at, is highly correlated with other two groups of PLC $\beta 1$ microarray data generated by probes 215687 _x_at and 211925_s_at. Correlation scores between microarray data of 213222_at and 215687_x_at and microarray data of 213222_at and 211925_s_at are 0.73099 and 0.79047 , respectively (Table 2 and Supplement Excel file). Data obtained by the 213222_at probe showed the highest geometric intensity and was chosen for our data analysis; the REMBRANDT database also uses this data as default for the Kaplan-Meier survival analysis. PLC $\beta 1$ microarray signal strength also yields a good correlation coefficient with other PN signature genes including DLL3 $(r=0.5)$, HEY2 $(r=0.5)$, Olig2 $(r=0.48)$, BCAN $(r=$ $0.62)$, and ERBB4 ( $r=0.62)$ [11]. PLC $\beta 1$ microarray signal strength, however, inversely correlates with YKL-40 ( $r=$ -0.59 ), one commonly used mesenchymal cell marker in dataset GDS1815.

\section{PLC $\beta 1$ Microarray Data Differentiates PN Subtype from Other HGG Subtypes in GDS1815}

Raw data histogram of one PLC $\beta 1$ probe (213222_at) is reproduced from the NIH website (Fig. 1a). The average
Table 2 Correlation coefficient between PLC $\beta 1$ expression and other signature genes [11] in GDS1815

\begin{tabular}{lll}
\hline Genes & Probes & $\begin{array}{l}\text { Coefficient with } \\
\text { PLC } \beta 1 \text { probe } \\
\text { 213222_at }(r=)\end{array}$ \\
\hline PLCß1 & 213222_at & 1 \\
& 215687_x_at & 0.73 \\
DLL3 & 211925_s_at & 0.79 \\
HEY2 & 219537_x_at & 0.50 \\
Olig2 & 219743_at & 0.50 \\
& 213825_at & 0.48 \\
BCAN & 213824_at & 0.37 \\
& 219107_at & 0.54 \\
ERBB4 & 221623_at & 0.64 \\
& 91920_at & 0.53 \\
YKL-40 & 214053_at & 0.62 \\
& 206794_at & 0.53 \\
& 209395_at & -0.47 \\
& 209396_s_at & -0.59 \\
& 216546_s_at & -0.30 \\
\hline
\end{tabular}

PLC $\beta 1$ signal strength is significantly lower in Mes $(n=33)$ than in PN subtypes $(n=15)$ among $\operatorname{GBM}(p<0.001$; Fig. 1 b). Furthermore, PLC $\beta 1$ expression results can potentially identify PN and Mes subtypes, regardless of whether samples are from primary or recurrent GBMs (Supplement data Figs. S1A and S1B). In combined samples of grade III and IV gliomas, the average PLC $\beta 1$ signal level in PN subtypes $(2642 \pm 207$, $n=37)$ is still significantly higher than its level in Mes ( $852 \pm$ $120, n=35)$ and in proliferative subtypes $(1242 \pm 170, n=28$; both $p<0.05)$. However, PLC $\beta 1$ content shows no statistical difference between Mes and proliferative subtypes $(p>0.05$; Fig. 1c).

\section{Validation of PLC $\beta 1$ as a PN Subtype Signature Gene in the TCGA Cohort}

In GBM cases from the TCGA cohort, PLC $\beta 1$ expression (RNA-Seq data) is significantly higher in the PN $(n=8)$ than that in the Mes subtype $(n=8 ; p<0.05$; Fig. 2a). While the difference between glyceraldehyde 3-phosphate dehydrogenase (GAPDH) expression levels in PN and Mes subtypes (Fig. 2b) is not statistically significant, GAPDH gene expression is commonly used as an endogenous control.

\section{PLC $\beta 1$ Expression Inversely Correlates with Glioma Pathological Grades}

Known PN subtype signature genes are not only useful in separating PN from Mes subtypes, but their expression levels also correlate with different grades of tumors. Both microarray 
A
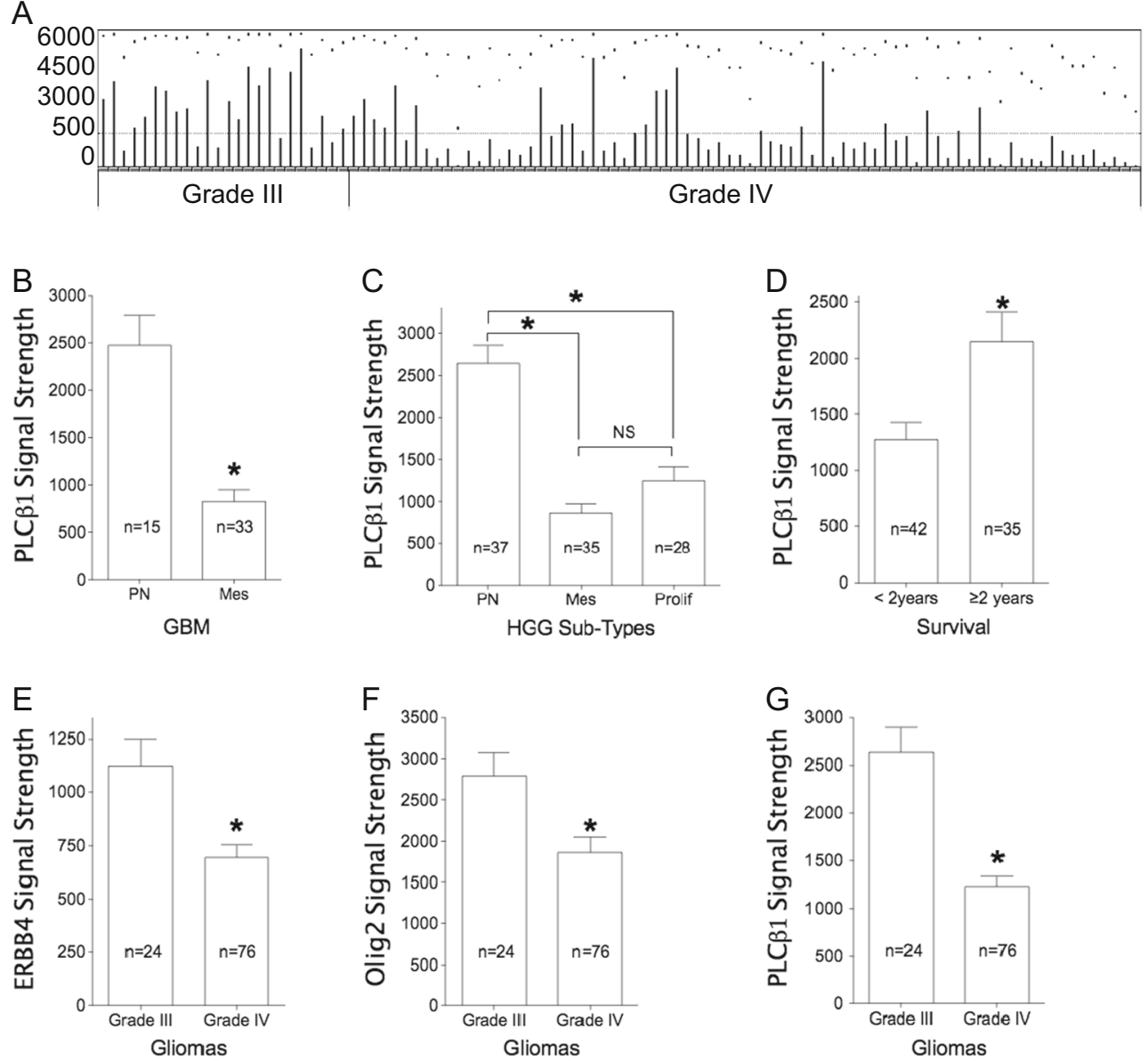

Fig. 1 a Original microarray data showing PLC $\beta 1$ signal strength in GDS1815 dataset from the NIH website with minor modification. b Analysis of data from grade IV samples, primary and recurrent tumors combined. Data shows a significant lower level of PLC $\beta 1$ in Mes $(n=33)$ subtypes than in PN $(n=15 ; * p=1.4 \mathrm{E}-4)$. c Analysis of combined samples of grades III and IV shows that the average PLC $\beta 1$ signal level in PN subtypes $(2642 \pm 207, n=37)$ is significantly higher than its level in Mes $(852 \pm 120, n=35 ; p=2.78 \mathrm{E}-10)$ and proliferative (Prolif) subtypes $(1242$ $\left.\pm 170, n=28 ; p=5.14 \mathrm{E}-6,{ }^{*} p<0.05\right)$. The difference between the PLC $\beta 1$ signal level in the Mes and proliferative subtype HGG is not statistically

significant $(p=0.126)$. NS nonsignificant. d In primary tumor cases, pooled data from grade III and grade IV gliomas shows that PLC $\beta 1$ microarray signal strengths are significantly higher in patients who survived over 2 years (mean $=240.3$ weeks, range 106 -477 weeks, $n=35$ ) than those survived less than 2 years (mean $=55.4$ weeks, range 3102 weeks, $n=42 ;{ }^{*} p=0.0035 ; 23$ cases do not have survival data). e- $\mathbf{g}$ ERBB4, Olig2, and PLC $\beta 1$ expression, respectively. All of these signal strengths are significantly lower in grade IV glioma samples $(n=76)$ than those in grade III gliomas $(n=24 ; * p<0.05)$

data of ERBB4 (Fig. 1e) and Olig2 (Fig. 1f), two known PN subtype signature genes, show significantly different expression levels between grade III and IV gliomas in GDS1815 dataset ( $p=0.01$ and 0.005 , respectively). In agreement with these two signature genes, PLC $\beta 1$ (Fig. 1g) also shows a significantly different expression between grade III $(n=24)$ and grade IV $(n=76)$ gliomas $(p<0.001)$.

We further validated the relationship between PLC $\beta 1$ expression and gliomas' pathological grades using other three independent GEO datasets (GDS2853, GDS1962, GDS1975). Specifically, GDS2853 studied low- $(n=8)$ and high-grade $(n=6)$ astrocytomas with 12,625 probes; GDS1962 studied nontumor controls $(n=23)$, grade II $(n=7)$ and III $(n=19)$ astrocytomas, GBM $(n=81)$, grade II $(n=37)$ and III $(n=13)$ oligodendrogliomas with 54,675 probes; and GDS1975 studied grade III [astrocytes $(n=8)$, mixed

oligoastrocytoma $(n=7)$, oligodendroglioma $(n=11)]$ and GBM $(n=59)$ with 22,283 probes. DGS1815, GDS1962, and GDS1975 used the same aforementioned three PLC $\beta 1$ probes, and we only did analysis of the data generated using probe 213222 at.

The GDS2853 gene expression profile revealed that the signal strength of the signature gene ERBB4 (Fig. 3a), but not Olig2 (Fig. 3b), was significantly different between lowgrade and high-grade astrocytomas; PLC $\beta 1$ data analysis agrees with ERBB4 in separating low-grade $(n=8)$ and highgrade $(n=6)$ tumors (Fig. $3 \mathrm{c} ; p=4.0 \mathrm{E}-4)$. In comparison, PLC $\beta 1$ raw data shows less variation than that seen in ERBB4 data.

Among all four GDS datasets, only GDS1962 (Fig. 4a) contained nontumor samples as controls. Figure $4 \mathrm{~b}$ shows that among all groups, the average PLC $\beta 1$ signal strengths were 
Fig. 2 HGG in TCGA only has a few cases that are labeled as Mes and PN subtypes. a Normalized PLC $\beta 1$ expression (RNA-Seq data) is significantly higher in PN $(n=8)$ than in Mes subtypes $(n=8$; $* p=4 \mathrm{E}-4)$. b In contrast, there is no statistical difference in GAPDH expression between PN and Mes subtypes $(p=0.41)$. $\mathbf{c}$ In the TCGA database, normalized PLC $\beta 1$ expression (RNA-Seq data) shows significant differences between grades II (10.87 \pm $0.05 ; n=212)$, III (10.23 \pm 0.08 ; $n=231)$, and IV

$(9.61 \pm 0.10 ; n=152 ; * p<0.0001)$. d GAPDH expression shows no significant difference between grades III $(15.56 \pm 0.03)$ and IV $(15.54 \pm 0.05 ; p=0.68) . N S$ nonsignificant. However, grade II gliomas $(15.41 \pm 0.03)$ contain less GAPDH than grade III $(p=0.017)$ and grade IV $(p=0.0018 ; * p<0.05)$
A

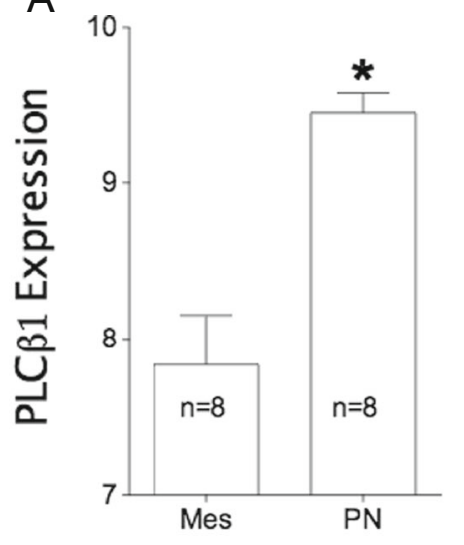

C

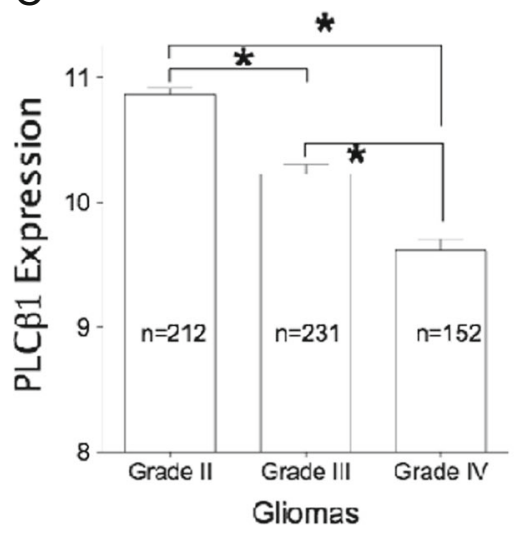

B

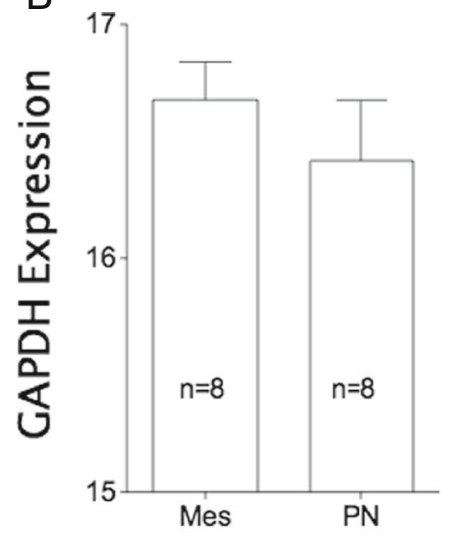

D

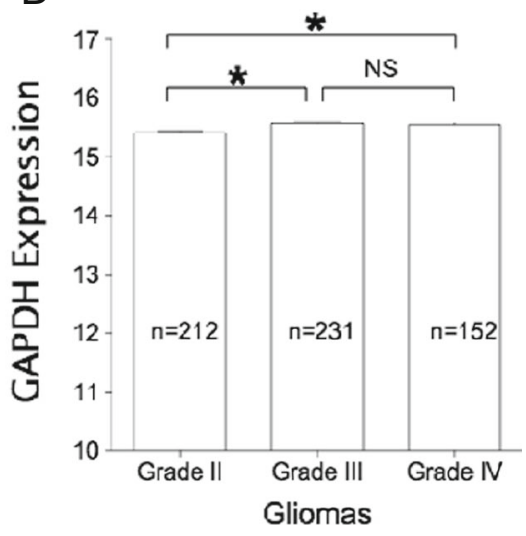

the highest in the nontumor controls $(n=23)$, followed by the grade II $(n=7)$, grade III $(n=19)$, and grade IV $(n=81)$ astrocytoma groups (Fig. 4b). The results that average PLC $\beta 1$ expression in grade III $(n=19)$ is significantly higher than in grade IV ( $n=81)$ astrocytoma (Fig. $4 \mathrm{~d} ; p=0.044)$ is consistent with previous analysis. The average PLC $\beta 1$ expression in nontumor controls $(n=23)$ is also significantly higher than in pooled data of all astrocytoma cases $(n=107, p=9.6 \mathrm{E}-9$;
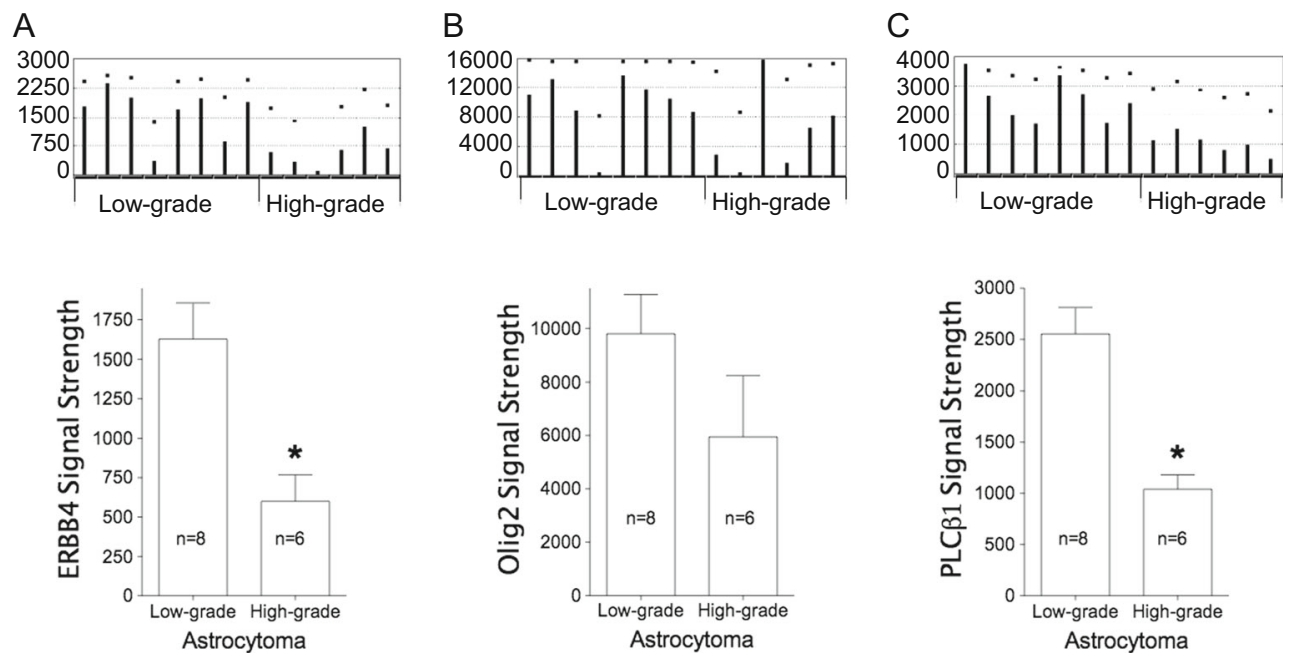

Fig. 3 ERBB4, Olig2, and PLC $\beta 1$ expressions presented as microarray data in low- and high-grade astrocytomas $(n=14)$. Original GDS2853 data from the NIH-maintained database are on top of each histogram. a, b ERBB4 and Olig2 microarray data used to do the same analysis; however, the ERBB4 signal was significantly reduced in high-grade samples
$(* p=0.0037)$, but the Olig2 signal $(p=0.19)$ was not. c PLC $\beta 1$ signal strength among high-grade astrocytoma samples $(n=6)$ significantly decreased in comparison to its signal from low-grade astrocytoma $(n=8$; $* p=0.0004$ ) 


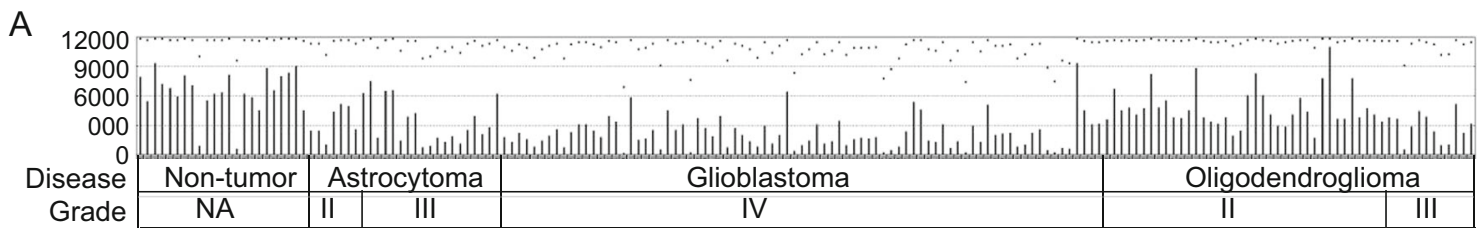

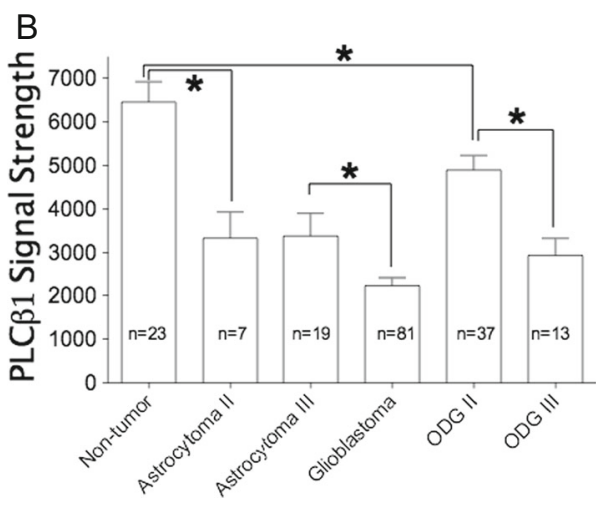

Fig. 4 Analysis of PLC $\beta 1$ expression profile from GDS1962. a Original microarray data copied from the NIH website with minor modification. $N A$ nonapplicable. b Collective PLC $\beta 1$ data analysis. Average PLC $\beta 1$ signal from nontumor controls $(n=23)$ is the highest, significantly higher than low-grade tumors including grade II astrocytomas $(n=7, p=$ $0.00097)$ and oligodendrogliomas $(n=37, p=0.0075)$. The average PLC $\beta 1$ signal from grade II $(n=37)$ is significantly higher than that from

Fig. 4c). We also analyzed oligodendroglioma cases separately and found that PLC $\beta 1$ expression is inversely related to pathological grades. Grade III $(n=13)$ oligodendroglioma has a significantly lower level than that of grade II $(n=37, p=7.0 \mathrm{E}-5$; Fig. S2A). Furthermore, overall oligodendroglioma samples $(n=50)$ showed significantly higher levels of PLC $\beta 1$ than astrocytomas ( $n=107, p=1.4 \mathrm{E}-6$; Fig. S2B). In GDS1975 [12], PLC $\beta 1$ expression was also significantly lower in grade IV $(n=$ 59) than in grade III gliomas ( $n=26, p=0.3 .0 \mathrm{E}-6$; Fig. S3).

Consistent with the outcomes of data analysis using GEO datasets, PLC $\beta 1$ expression level (RNA-Seq data) inversely correlates with pathological grades (II, III, and IV) in the TCGA (Fig. 2c), while GAPDH data shows less significant difference among subtype groups and no significant difference between grades III and IV (Fig. 2d). GAPDH is commonly used as the internal control. Thus, we summarize this inverse relationship between PLC $\beta 1$ expression and glioma pathological grades in diagram (Fig. 8).

\section{PLC $\beta 1$ Expression Is Closely Associated with Patient Survival in the REMBRANDT Cohort}

Gene expression profiling of gliomas has been studied to predict patient survival [12]. We analyzed the relationship between PLC $\beta 1$ gene expression using probe 213222 at and patient survival information in the REMBRANDT cohort. Glioma are stratified into groups based on PLC $\beta 1$ expression: 103 cases in the intermediate group, 226 cases in the
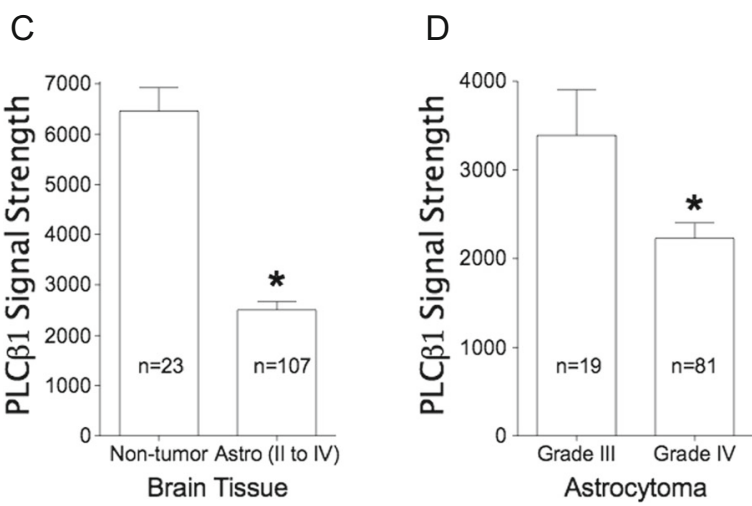

grade III $(n=13)$ oligodendroglioma $(p=7.42 \mathrm{E}-05)$. $\mathbf{c}$ PLC $\beta 1$ signal levels from nontumor controls $(n=23)$ are significantly higher than those from astrocytomas cases (Astro, $n=107, \mathrm{p}=9.63 \mathrm{E}-09$ ), grades II to IV combined. d PLC $\beta 1$ signal levels from grade III $(n=19)$ astrocytomas are significantly higher than from grade IV astrocytomas $(n=81 ; * p=$ $0.044)$

downregulated ( $\geq 2 X)$ group, and 0 cases in the PLC $\beta 1$ upregulation $(\geq 2 \mathrm{X}$ ) group. When analyzing PLC $\beta 1$ expression level in glioma subclass, astrocytoma cases are stratified into intermediate $(n=48)$ and downregulated $(\geq 2 \mathrm{X})$ groups $(n=$ 57); there is no upregulated group (Fig. 5a, b). Log-rank test results show significant differences between the intermediate PLC $\beta 1$ group and the PLC $\beta 1$ downregulated groups for glioma $(p=3.0 \mathrm{E}-09)$ and its subclass astrocytoma $(p=2.0 \mathrm{E}-04)$ in a Kaplan-Meier survival plot. When PLC $\beta 1$ expression is further stratified as $3 \mathrm{X}, 4 \mathrm{X}, 5 \mathrm{X}, 6 \mathrm{X}$, and $7 \mathrm{X}$ downregulation in glioma cases, log-rank tests still show significant differences between intermediate and downregulated groups (Table 4). When PLC $\beta 1$ expression is stratified by $3 \mathrm{X}$ downregulation in astrocytoma cases, the survival curve is still significantly different in the intermediate group compared to the downregulated PLC $\beta 1$ groups $(p=0.018)$ (Table 4$)$. GAPDH expression is normalized internally among all cases (Fig. 5c, d).

Similar to a Kaplan-Meier survival curve for samples of differential PLC $\beta 1$ gene expression, subgroups can also be stratified by different ERBB4 expression. However, different levels of ERBB4 expression are only associated with survival in all glioma cases, but fail to show statistical significance among glioma subclass astrocytoma cases (Supplement Figs. S4A and S4B). We also conducted an analysis of a Kaplan-Meier survival plot for samples with differential Olig2 gene expression. Olig2 gene expression presents as bidirectional (up- and downregulation) changes in astrocytoma cases $(n=105)$, but there is no statistical significance in 
A

\section{PLC $\beta 1$}

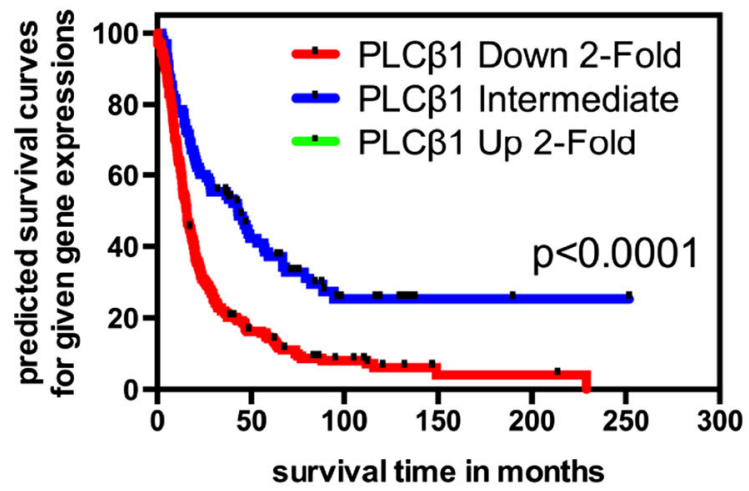

C

\section{GAPDH}

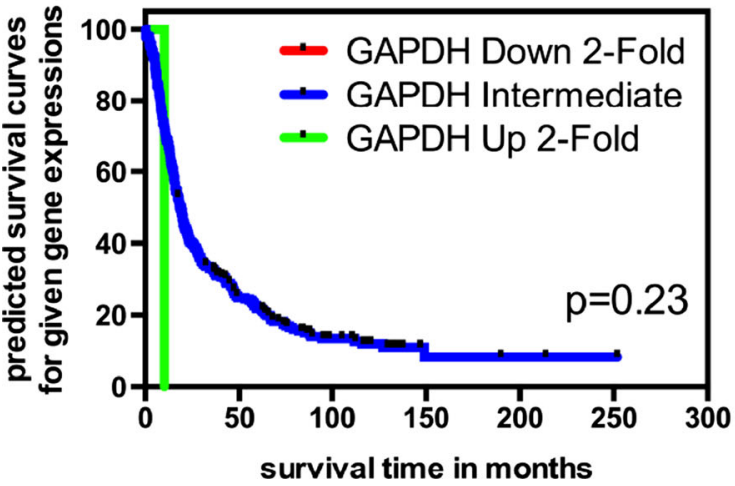

Fig. 5 Kaplan-Meier survival curve for samples with differential PLC $\beta 1$ and GAPDH gene expression, respectively; raw data extracted from the REMBRANDT cohort. a PLC $\beta 1$ downregulated glioma patients $(n=$ 226) had significantly shorter survival times than intermediate level PLC $\beta 1$ glioma patients $(n=103)$ per the log-rank test $(p=3.0 \mathrm{E}-09)$. b PLC $\beta 1$ downregulated astrocytoma patients $(n=57)$ survived significantly shorter than the intermediate level PLC $\beta 1$ astrocytoma patients $(n=45)$ per the log-rank test $(p=2.0 \mathrm{E}-04)$. Both databases contain no cases stratified as upregulated PLC $\beta 1$ expression ( $\geq 2 X)$. $\mathbf{c}$ Based on GAPDH expression level, only 1 glioma case is classified as upregulated $(\geq 2 X)$, not

survival outcome among Olig2 gene upregulated $(n=62)$, intermediate level $(n=33)$, and downregulated $(n=10)$ subgroups $(p>0.05)$ (data not shown).

\section{PLC $\beta 1$ Expression Is Closely Associated with Patient Survival in the TCGA Cohort and GDS1815}

The TCGA cohort was also analyzed via a Kaplan-Meier survival curve based on PLC $\beta 1$ expression levels (RNA-Seq data). In a combination of all cases available from grades II to IV $(n=587)$, patients in the top $50 \%$ of PLC $\beta 1$ expression group $(n=294)$ survived on average 88.7 months, significantly longer than those of the bottom $50 \%$ percentile of PLC $\beta 1$ expression $(n=293)$ who survived on average 21.6 months ( $p=4.8 \mathrm{E}-12$; Fig. $6 \mathrm{a})$. In analyzing data solely from GBM cases, which as a group contains the lowest PLC $\beta 1$
B

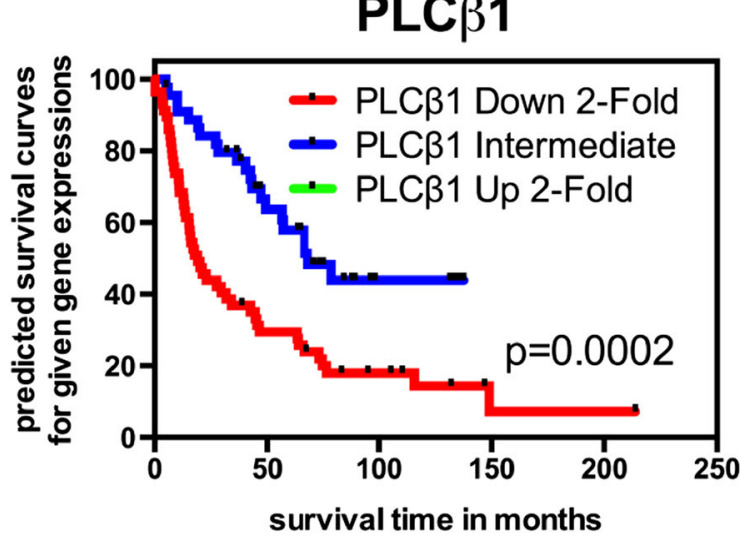

D

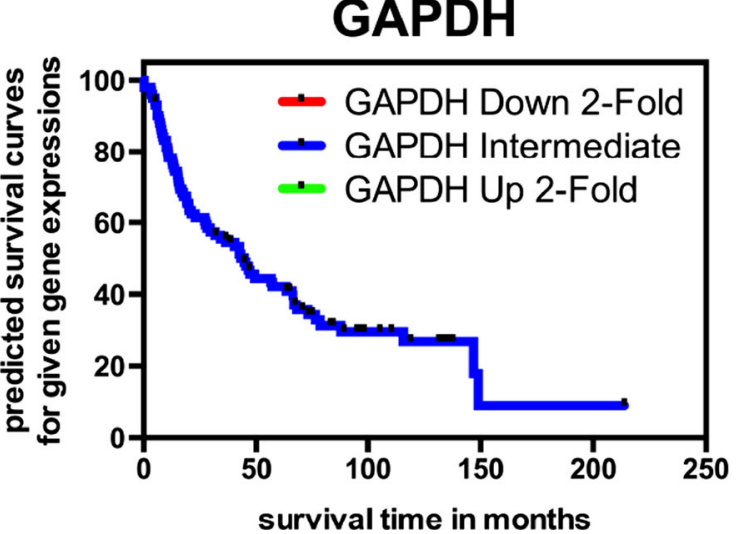

statistically significant in survival from the group of intermediate level GAPDH $(n=328 ; p=0.23)$. There are no GAPDH downregulated glioma patients $(n=0)$. d Based on the GAPDH expression level, there are no astrocytoma cases being classified as up- $(n=0)$ or downregulated $(n=0)$ exceeding 2-fold. Intermediate level of GAPDH is the only group ( $n=$ 102). Note: Among the raw data we downloaded for analysis, 14 glioma cases (include 3 astrocytoma) lacked censored information. Thus, our analysis has 14 fewer glioma cases (include 3 astrocytoma) than the total cases reported in the REMBRANDT website (see Table 4)

expression level, only subjects with top $5 \%$ PLC $\beta 1$ expression $(n=9$, mean $=25.7$ months) survive significantly longer than the lower $95 \%$ subjects $(n=142$, mean $=13.2$ months, $p=$ 0.039; Fig. 6b). Results from analysis of the top $10 \%$ versus the rest of the $90 \%$, and top versus bottom $50 \%$ of PLC $\beta 1$ expressions, show no significant survival differences among GBMs (data not shown).

GDS1815 data can be used to evaluate the prognostic value of candidate genes because it contains information about patient age, survival, and tumor grades (Supplement Excel spread sheet). We found that the patients who died in fewer than 104 weeks (median duration $=55.4$ weeks, range 3102 weeks, $n=42$ ) had a significantly lower level of PLC $\beta 1$ than those who survived 104 weeks and longer (median duration $=240.3$ weeks, range $106-477$ weeks, $n=35$; Fig. $1 \mathrm{~d}, p=$ $0.0035)$. Here we combined grade III and grade IV glioma for 


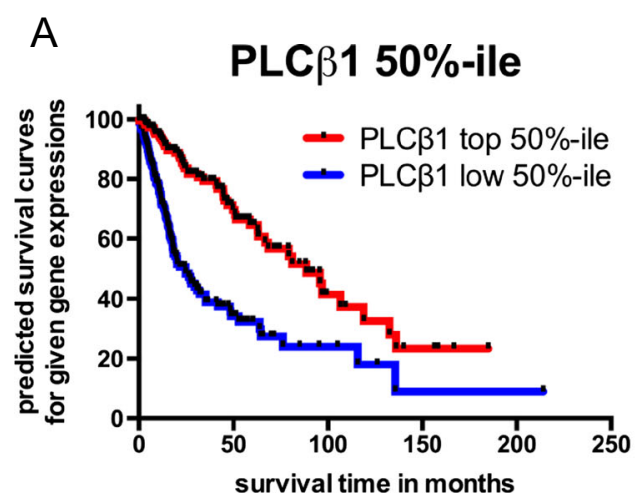

Fig. 6 Kaplan-Meier survival curve for samples with differential PLC $\beta 1$ gene expression from the TCGA cohort. a Merged grade II-IV gliomas are stratified as high $(n=294)$ and low $50 \%$ PLC $\beta 1$ expression $(n=293)$. There is statistical difference in survival between the two groups as

data analysis since each subgroup contains only a small number of cases.

\section{PLC $\beta 1$ Expression in Human Glioma Samples}

Images from the HPA website show that all four PLC $\beta 1$ antibodies stain cortical neurons of their cell bodies and neuropils, without staining glial cells in normal cerebral cortex (Fig. 7a). The majority of reports show negative PLC $\beta 1$ staining in glioma cells (Fig. 7b); both HPA057910 and CAB004275 antibodies yield negative staining in glioma cells in 11 glioma samples (data not shown). Only HPA034743 and CAB005334 show different intensities of positive staining in glioma tumor cells. Interestingly, from the same group, all HPA034743 staining is restricted to nuclei (Fig. 7c), while all CAB005334 staining is located at cytoplasm and cell membrane (Fig. 7d). We summarize the pathological report from these 11 patients and PLC $\beta 1$ staining in Table 3.

\section{Discussion}

Glioma, the collective name for astrocytomas (grades I-IV), oligodendrogliomas (grades II-III), oligoastrocytomas (grades II-III), and ependymomas, is the most common primary brain tumor in adults [30]. Managing of high grade gliomas, especially GBM, remains a challenge in clinical practice due to the complexity of the multicellular background and genetic heterogeneity. We analyzed four independent microarray datasets from the NIH-maintained GEO databases, REMBRANDT, and the TCGA database and found that PLC $\beta 1$ gene expression (microarray and RNA-Seq) level is inversely correlated with gliomas' pathological grades; it is a potential novel signature gene in subclassifying HGG into PN versus other subtypes, and its expression level also correlates with patients' survival. Our study provides evidence for the
B

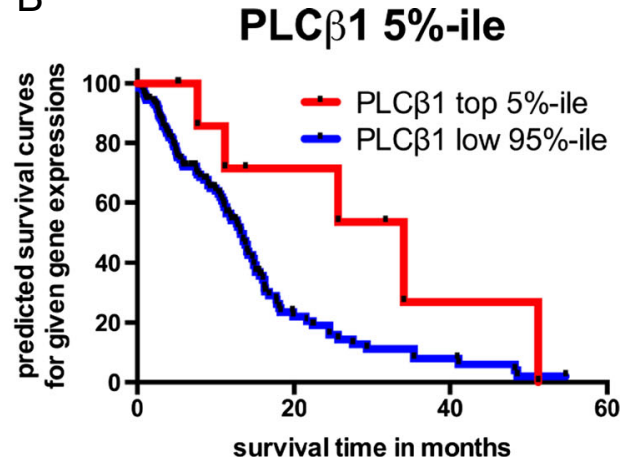

indicated by the log-rank test ( $p=4.8 \mathrm{E}-12)$. b GBM cases are stratified into the highest $5 \%$ expression $(n=9)$ and the rest of $95 \%(n=142)$; there is statistical difference in survival between the two groups as indicated by the log-rank test $(p=0.039)$

first time that PLC $\beta 1$ is a candidate signature gene for PN subtype of HGG.

Previous research has highly recommended integrating molecular findings in current WHO classifications in order to generate a new histomolecular classification guideline [3, 8]. For instance, promoter methylation status of DNA repair enzyme $O^{6}$-methylguanine-DNA methyltransferase (MGMT), which affects patient chemosensitivity to temozolomide, has become a frequently requested laboratory test in neuro-oncology [4]. Patients with $\mathrm{CpG}$ island hypermethylation (G-CIMP) and isocitrate dehydrogenase 1 (IDH1) mutation have better prognoses [31, 32]. However, IDH1 mutation $(\sim 10 \%)$ and G-CIMP methylation positive ( $\sim 9)$ only account for a small percentage of primary GBM $[33,34]$. IDH mutated glioma patients are significantly younger than those with IDH wild type, and IDH1/2 mutation is strongly associated with low grade astrocytomas. Paul Mazaris and his colleagues demonstrated that none of $31 \mathrm{GBM}$ samples being tested harbored either IDH1 or IDH2 mutation [35]. Furthermore, studies demonstrated that prognostic signature genes that work well in long-term GBM survivors who have IDH mutations have no predictive value in IDH wild-type cases [36]. Thus, analysis of single gene mutations and/or epigenetic modifications are useful but have limitations in clinical practice. Novel classification of gliomas based on gene expression has shed light to better understanding of glioma pathogenesis in recent years. For example, Phillips et al. used 35 signature genes to classify 183 GBM samples into three subtypes: $31 \%$ were PN, $20 \%$ were proliferative, and $49 \%$ were Mes subtypes. Clinical studies had demonstrated that patients with tumors displaying PN signature gene markers live longer, while those tumors have Mes signature genes had much shorter survival times (174.5 weeks for PN subtypes vs. 65 weeks for Mes subtypes) [11]. Per report by Verhaak and colleagues, patients with Mes subtypes respond favorably to standard treatment (temozolomide and radiation) and treatment 
A

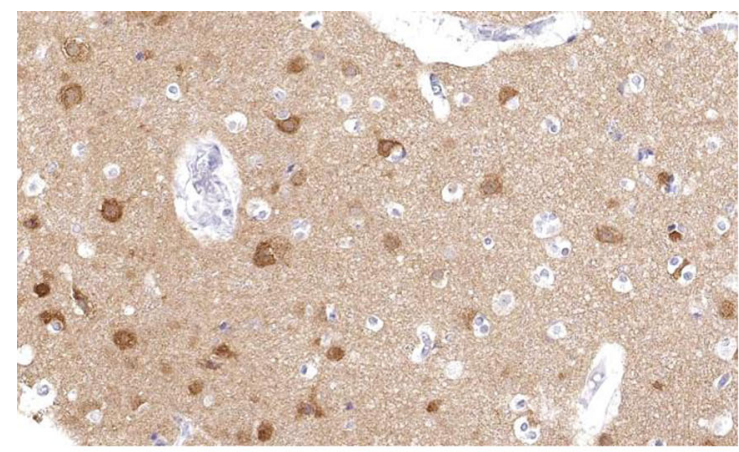

C

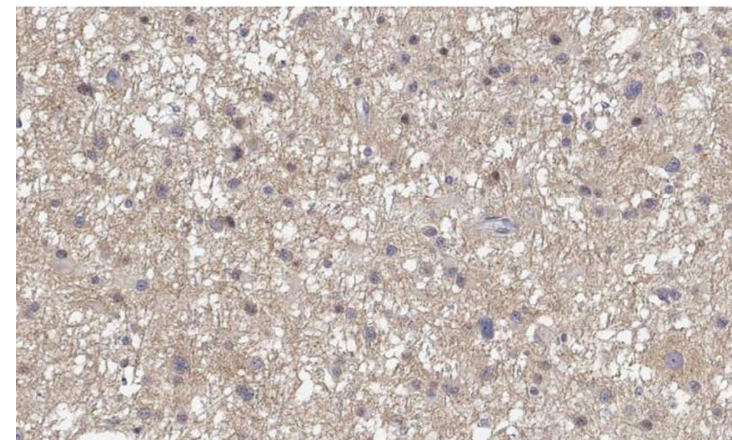

Fig. 7 IHC images obtained from the HPA website. Antibody CAB005334 is used for images a-c, HPA034743 antibody is used for d. a PLC $\beta 1$ staining from normal cerebral cortex tissue of a 52-year-old female subject (patient ID - 3740). b Negative PLC $\beta 1$ staining of glioma

significantly prolonged their survival, but PN subtypes do not benefit as much from these same treatments [10].
B

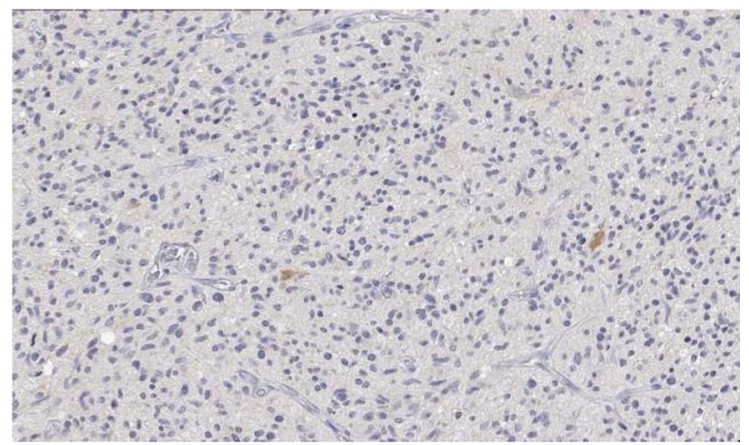

D

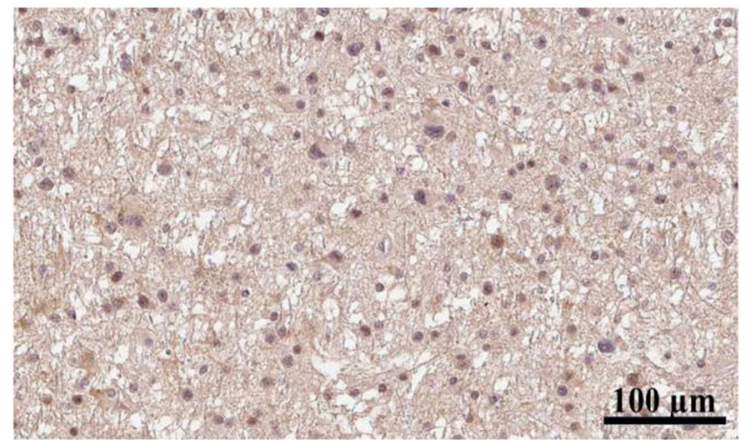

from a 75-year-old male subject (patient ID-2851). Both $\mathbf{c}$ and $\mathbf{d}$ are from one 32-year-old female subject (patient ID-122). c Cytoplasmic/ membranous stain of PLC $\beta 1$ in glioma cells. $\mathbf{d}$ Nuclear stain of PLC $\beta 1$ in glioma cells. Bar scale equals to $100 \mu \mathrm{m}$

PLC $\beta$ has four isoforms, all of which can be detected in the brain. Only one or two isoforms, however, are predominantly

Table 3 Summary of pathology report about PLC $\beta 1$ antibodies staining in tumor cells from patients' glioma IHC (source: Human Protein Atlas http:// www.proteinatlas.org/)

\begin{tabular}{|c|c|c|c|c|c|c|c|c|c|}
\hline \multirow[t]{2}{*}{ Patient ID } & \multirow[t]{2}{*}{ Tumor Grade } & \multirow[t]{2}{*}{ Sex } & \multirow[t]{2}{*}{ Age } & \multicolumn{3}{|c|}{ CAB005334, Santa Cruz Biotechnology } & \multicolumn{3}{|c|}{ HPA034743, Sigma-Aldrich } \\
\hline & & & & Intensity & Quantity & Location & Intensity & Quantity & Location \\
\hline 122 & Low & $\mathrm{F}$ & 32 & Weak & $<25 \%$ & Cytoplasmic/membranous & Moderate & $75 \%-25 \%$ & Nuclear \\
\hline 2892 & Low & $\mathrm{F}$ & 55 & Moderate & $<25 \%$ & Cytoplasmic/membranous & Weak & $<25 \%$ & Nuclear \\
\hline 2895 & Low & M & 66 & Negative & Negative & None & Weak & $<25 \%$ & Nuclear \\
\hline 2909 & Low & M & 43 & Weak & $<25 \%$ & Cytoplasmic/membranous & Weak & $>75 \%$ & Nuclear \\
\hline 45 & High & M & 72 & Negative & Negative & None & Weak & $<25 \%$ & Nuclear \\
\hline 2849 & High & M & 54 & Weak & $<25 \%$ & Cytoplasmic/membranous & Weak & $<25 \%$ & Nuclear \\
\hline 2850 & High & M & 54 & Negative & Negative & None & Weak & $75 \%-25 \%$ & Nuclear \\
\hline 2851 & High & M & 75 & Negative & Negative & None & Weak & $75 \%-25 \%$ & Nuclear \\
\hline 2862 & High & $\mathrm{F}$ & 40 & Negative & Negative & None & Weak & $75 \%-25 \%$ & Nuclear \\
\hline 2891 & High & M & 49 & Negative & Negative & None & Negative & Negative & None \\
\hline 2907 & High & M & 76 & Negative & Negative & None & Weak & $<25 \%$ & Nuclear \\
\hline
\end{tabular}

Note: data is ranked by tumor grade and then patient ID. IHC reports using the other two antibodies (HPA057910 and CAB004275) are not listed because all results are negative. $M$ male, $F$ female. 
expressed in neurons $[16,37]$. PLC $\beta 1$, the predominant isoform in neurons, is involved in signal transduction in the cerebral cortex and hippocampus via its coupling to the muscarinic acetylcholine receptor [38]. It regulates neurogenesis since the knockout PLC $\beta 1$ gene affects cortical barrel formation in mouse model [18]. The PLC $\beta 1$ expression from the prefrontal cortex of developing human brain displays in an age-specific manner, suggesting that PLC $\beta 1$ is playing an important role in the differentiation and maturation of neurons in the developing brain [39]. Oligodendrocytes are also known to express intermediate levels of PLC $\beta 1$; astrocytes express the lowest level under culture conditions [20]. We theorize that this outcome is just inducible under culture conditions in vitro because freshly isolated glial cells are negative of PLC $\beta 1$ expression by PCR amplification [21, 22]. Thus, the finding that PLC $\beta 1$ expression was detected in glioma tissues by different methods such as microarray, RNA-Seq, and IHC indicates a very meaningful and possibly a pathological change. Furthermore, PLC $\beta 1$ microarray signal strength correlates well with other PN signature genes including DLL3, HEY2, Olig2, BCAN, and ERBB4 and negatively correlates with YKL-40 (Table 2 and Supplement Excel file), one commonly used mesenchymal cellular marker in dataset GDS1815. Grouping with the listed PN signature genes makes PLC $\beta 1$ another candidate signature gene for PN subtype glioma. Most of the microarray studies used three PLC $\beta 1$ probes; the original data generated by three probes in GDS1815 are highly correlated with one another (Supplement Excel spread sheet), which confirmed that these probes are of high specificity and binding efficacy; thus, users can be assured the data is of high reliability.

PLC $\beta 1$ gene expression inversely correlate with tumor grades (III and IV) and survival among glioma patients in GDS1815 dataset (Fig. 1), the presence of PLC $\beta 1$ transcripts are associated with PN subtype GBM from Mes (Figs. 1b and 2) and proliferative subtypes (Fig. 1c). Average PLC $\beta 1$ signal strength is also useful in separating grade III from grade IV HGG in GDS1962 (Fig. 4). Average PLC $\beta 1$ levels from normal tissue controls are significantly higher than those from low-grade tumors and its level is further downregulated in higher grade tumors, including astrocytomas and oligodendrogliomas in GDS1962 (Figs. 4 and S2). Because the TCGA database contains data for GBM as well as grade II/ III gliomas, we merged these data and performed an analysis after removing batch effects. Normalized PLC $\beta 1$ expression inversely correlates with pathological grades of glioma: the higher the pathological grade, the lower the PLC $\beta 1$ expression $(p<0.0001$, Fig. $2 c)$. In contrast, GAPDH data showed no significant difference between grades III and IV samples, though grade II samples contain significantly lower amount of GAPDH than in HGG samples ( $p<0.05$; Fig. 2 d).

A Kaplan-Meier survival curve of both REMBRANDT [glioma (Fig. 5a) and astrocytoma (Fig. 5b)] and TCGA data [grade II to IV merged (Fig. 6a) and GBM (Fig. 6b)] showed that different subgroups of PLC $\beta 1$ microarray/RNA-Seq expression levels correlate well with patient survival $(p<0.05)$. It is worth mentioning that only the top $5 \%$ of PLC $\beta 1$ expression $(n=9)$ of GBM cases survived significantly longer than the rest of $95 \%$ of PLC $\beta 1$ expression ( $n=142$ ) (Fig. 6b). However, the top $10 \%$ and top $50 \%$ PLC $\beta 1$ expression groups did not show survival benefits over the rest (data not shown). We believe that the GBM group contains the lowest level of PLC $\beta 1$ transcripts based on our analysis, but because there are many other factors affecting PLC $\beta 1$ signals (see discussion below), it is difficult to isolate a subgroup with statistically significantly "high" PLC $\beta 1$ expression than others. This reason may also explain why the REMBRANDT cohort analysis shows no statistical significant difference in survival among GBM cases (data not shown). ERBB4 expression level also shows unidirectional reduction as PLC $\beta 1$ does in the current analysis of the REMBRANDT cohort. Interestingly, a Kaplan-Meier survival curve demonstrates statistical significance among the stratified groups based on PLC $\beta 1$ expression in glioma and its subclass astrocytoma, while a Kaplan-Meier survival curve based on different ERBB4 expression levels only shows statistical significance among stratified glioma cases, but fails to show statistical significance among astrocytoma cases (Supplement S4). In GDS1815, when combining data from grade III and IV glioma, PLC $\beta 1$ level is significantly different between two groups of patients: $<2$ years $(n=48)$ vs. over 2 years survival $(n=35)$ (Fig. 1d). Thus, this unique application of PLC $\beta 1$ gene expression in predicting patient survival deserves further study in a large cohort from patients perspectively (Table 4).

PLC $\beta 1$ level in gliomas was not only useful in the separation of low- and high-grade astrocytomas, but also has significant differences between grades II (low-grade) and III (high-grade) oligodendrogliomas (Fig. 4b and S4). Okamoto et al. [1] demonstrated that patients with oligodendrogliomas have the highest survival rate (78 \% at 5 years, $51 \%$ at 10 years), followed by those with oligoastrocytomas ( $70 \%$ at 5 years, $49 \%$ at 10 years), and fibrillary astrocytomas (65\% at 5 years, $31 \%$ at 10 years). Survival of patients with gemistocytic astrocytomas was the poorest (16\% at 5 years and $0 \%$ at 10 years). Confirming this observation, our data analysis showed that PLC $\beta 1$ signal in oligodendroglioma is significantly higher than that in pooled data of astrocytomas (Fig. S2B). A cellular study also demonstrated that PLC $\beta 1$ expression levels in oligodendrocytes were higher than that in astrocytes [20], a finding that may be useful in interpreting the clinical outcome whereby oligodendroglioma patients usually have a better prognosis than astrocytoma patients. Interestingly, GBM patients with an oligodendroglial component $(n=57)$ who survived longer (12 vs. 5.8 months; $p=$ 0.006 ), comparing to 50 cases of other primary GBM, showed no difference in the frequency of common genetic defects, such as loss of heterozygosity of chromosome 1p/19q, MGMT promoter methylation, or IDH1 mutation [40]. We believe that 
Table 4 Kaplan-Meier survival analysis based on PLC $\beta 1$ gene expression level changes

\begin{tabular}{clllll}
\hline & $\begin{array}{l}\text { Stratification } \\
\text { (by PLC } \beta 1 \\
\text { downregulation) }\end{array}$ & Upregulated & Downregulated & $\begin{array}{l}\text { Intermediate } \\
\text { level }\end{array}$ & $\begin{array}{l}p \text { value } \\
\text { (downregulated } \\
\text { vs. intermediate) }\end{array}$ \\
\hline Glioma $(n=343)$ & $2 \mathrm{X}$ & 0 & 235 & 108 & $3.0 \mathrm{E}-09$ \\
& $3 \mathrm{X}$ & 0 & 163 & 180 & $2.5 \mathrm{E}-08$ \\
& $4 \mathrm{X}$ & 0 & 122 & 221 & $4.0 \mathrm{E}-09$ \\
& $5 \mathrm{X}$ & 0 & 86 & 257 & $3.9 \mathrm{E}-06$ \\
& $6 \mathrm{X}$ & 0 & 69 & 274 & $1.6 \mathrm{E}-05$ \\
Astrocytoma & $2 \mathrm{X}$ & 0 & 54 & 289 & $7.9 \mathrm{E}-05$ \\
$(n=105)$ & $3 \mathrm{X}$ & 0 & 57 & 48 & $2.0 \mathrm{E}-04$ \\
& & 0 & 33 & 72 & 0.018 \\
\hline
\end{tabular}

PLC $\beta 1$ expression status may provide valuable information in the scenario when all known biomarkers are unrevealing. Separate from other known cancer biomarkers, which are usually upregulated at different stages of a disease, PLC $\beta 1$ expression level is the highest in normal tissues. Glioma samples show unidirectional reduction regarding PLC $\beta 1$ expression-the higher the pathological grade, the lower the level of PLC $\beta 1$ expression (microarray and RNA-Seq data). In addition, the REMBRANDT database only stratifies brain tumors as PLC $\beta 1$ "intermediate" and "downregulated" groups, in contrast to most of the other genes, which usually present as bidirectional changes. There is no subject in the "upregulated" group. This raises the possibility that overall PLC $\beta 1$ signal from glioma tumors is mainly determined by residual neurons, which harbor much higher levels of PLC $\beta 1$ than other cell types. The detected PLC $\beta 1$ level from gliomas is possibly a logical reflection of residual neurons' PLC $\beta 1$ content, which will diminish as the tumor cells expand. PLC $\beta 1$ originating from glioma cells, if there is any, only contributes partially to measurable PLC $\beta 1$ gene expression.

Gliomas may originate from mixed cell types including oligodendrocytes and astrocytes as well as mesenchymal, neuroepithelial cells and cancer stem cells. However, the extent to which each cell type contributes to the overall level of PLC $\beta 1$ detected in patient tumor tissue has not been well studied. There are reports that glioma cell lines contain detectable PLC $\beta 1$; however, no information is available as to whether mesenchymal cells, despite being one of the common types of cells identified in glioma, express PLC $\beta 1$. Thus, it will be necessary to study cellular origins of PLC $\beta 1$ expression in gliomas to determine if different levels of PLC $\beta 1$ expression actually originate from oligodendrocytes, astrocytes, or even possibly mesenchymal cells versus normal and abnormal neuroprogenitor cells, or neurons.

Predominantly, cytoplasmic PLC $\beta 1$ expression occurs in neurons and their synapses and neuropils. As a result, abnormal PLC $\beta 1$ expression has been studied for its role in neurological diseases extensively such as seizure and epilepsy [41, 42]. In the analysis of The Catalogue of Somatic Mutations in
Cancer, Mark G. Waugh demonstrated that the change in the number of gene copies of PLC $\beta 1$, as a component of phosphoinositide pathway, is involved in GBM; however, their conclusion that GBM cells gain PLC $\beta 1$ gene copies is different from our findings [43].

Accumulating evidence suggests a pathological role of PLC $\beta 1$ in glioma abnormality. Rodent studies showed that PLC $\beta 1$ expression is undetectable by PCR from freshly isolated astrocytes, but it can be detected in established astrocytoma cell lines and C6 rat glioma cell lines [15, 20-23]. Interestingly, PLC $\beta 1$ expression is inducible from primary cultured astrocytes when stimulated with lipopolysaccharide [22]. Pathological reports from the Human Protein Atlas show that PLC $\beta 1$ antibodies mainly stain neurons and neuropils in a normal brain without staining glial cells (Fig. 7a) [44]. However, some glioma samples are stained with PLC $\beta 1$ antibodies, both cytoplasmic and inside nucleus (Fig. 7c, d). These stains from human gliomas demonstrate that astrocytes can be induced to express PLC $\beta 1$ under pathological conditions.

PLC $\beta 1$ has two ( $a$ and $b)$ isoforms which are different in their $\mathrm{C}$ terminals, and both isoforms contain a nuclear localization signal domain $[45,46]$. Nucleus presence of PLC $\beta 1$ was demonstrated in cortical neurons of rabbit brain [15, 47], and evidence demonstrated that two isoforms have their preference in the cytosol and nuclear of C6 glioma cells, respectively [23]; PLC $\beta 1$ was also shown to be transited into the nucleus among C6 glial cell and Neuro2A cell (mouse neuroblastoma cell line) under stimuli [48]. Inside the nuclear, PLC $\beta 1$ is one of the key molecules that regulate nuclear inositides, and latest research concludes that nuclear inositides are independently regulated and nuclear inositol lipids themselves can modulate nuclear processes, such as transcription and pre-mRNA splicing, growth, proliferation, cell cycle regulation, and differentiation [49].

There have been no study found PLC $\beta 1$-mediated signaling in gliomas, and we speculate that PLC $\beta 1$ may play a role in glioma tumorigenesis. It has been demonstrated in hematological diseases including myelodysplastic syndromes and leukemia [50, 51] and other neurological diseases [52]. PLC $\beta 1$ and phosphoinositide 3-kinase (PI3K) share the common 
substrate PIP2. Thus PLC $\beta 1$ 's activity regulates the availability of cellular PIP2 content in theory. Upon stimuli, PI3K converts PIP2 to phosphatidylinositol 3,4,5-trisphosphate (PIP3), which leads to cascade downstream reaction involving AKT and mTOR. Evidence exists that PLC $\beta 1$ interconnected with $\mathrm{PI} 3 \mathrm{~K} / \mathrm{AKT} / \mathrm{mTOR}$ signaling in solid tumors and hematological malignancies [49, 53]. In a study of pro-B-lymphoblastic cell, b isoform PLC $\beta 1$ promotes cell survival by affecting AKT activation, cyclin E expression, and caspase cleavage [54]. In addition, our analysis demonstrates that PLC $\beta 1$ gene expression level correlates the best with glioma PN signature gene ERBB4. ERBB4 protein is a tyrosine-protein kinase and a member of the epidermal growth factor receptor subfamily, which contributes to glioma pathogenesis. At the protein level, typical ERBB4 signaling in the central nervous system involves downstream PLC and PI3K-AKT activation; cleaved intracellular fragment translocates into nucleus and regulates gene transcription [52]; cleaved ERBB4 protein also plays an important role in regulating the timing of astrogenesis in the developing brain [55]. It is worth to mention that ERBB4 expression is mainly restricted within neurons $[56,57]$ like PLC $\beta 1$ does among mature rodent brains, not commonly expressing a high level among astrocytes. It is possible that ERBB4 and PLC $\beta 1$, as neuron predominant proteins, contribute to glioma tumorigenesis or progression.

As shown in this study, the PLC $\beta 1$ signal strength varies among samples and in the same subgroups. Since microarray signal strength and RNA sequencing reflects mRNA content in transcriptome, mRNA stability or instability, different amount of normal tissue mixed into the tumor samples can contribute to this. Factors such as tissue sampling and storage condition, sample processing time lag from initial tissue harvesting, treatment regimen (chemo- and radiotherapy) and time length, primary versus recurrent tumor, tumor pathological grades, and classification could all contribute to a wide

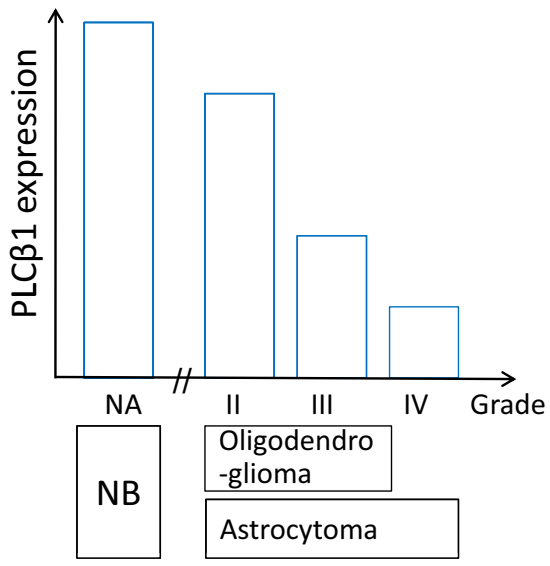

Fig. 8 Graphic diagram displays a relationship between glioma PLC $\beta 1$ expression and pathological grades. Normal brain $(N B)$ expresses the highest level of PLC $\beta 1$. Among the astrocytomas, the higher the pathological grade (II to IV), the lower is the PLC $\beta 1$ expression. This inverse relationship also applies to oligodendrogliomas (grades II and III) variation of PLC $\beta 1$ expression detected. In addition, PLC $\beta 1$ microarray probes only target and bind to common cDNA region of both $\mathrm{a}$ and $\mathrm{b}$ isoforms; however, two isoforms are different in their $\mathrm{C}$ terminals; thus, microarray data based on current PLC $\beta 1$ probes could not differentiate the a or $\mathrm{b}$ isoform. If the transcription of one PLC $\beta 1$ isoform is predominant isoform, the minor component of overall PLC $\beta 1$ signal may not contribute to our conclusion reached in this study: the higher the glioma grade, the lower the PLC $\beta 1$ expression. It will be possible for one isoform to gain its signal strength along with pathological grades. More research is certainly needed to substantiate this observation.

In summary, our data analyses of TCGA and four independent GEO datasets revealed an association between differential expression of PLC $\beta 1$ and glioma pathological grades (Fig. 8). PLC $\beta 1$ is a potential novel signature gene for PN subtypes in molecular classification of HGG because its gene expression correlates with known PN subtype signature genes; its inducible property in glial cells further supports its role as a biomarker in glioma classification. Kaplan-Meier survival curves based on differential PLC $\beta 1$ gene expression from the REMBRANDT and TCGA cohorts also demonstrate that high level of PLC $\beta 1$ expression associates with patient's long-term survival. Quantitative PLC $\beta 1$ microarray/RNA-Seq result(s) could be incorporated with current molecular assay tools to supplement tradiational neuropathology in classifying HGG subtype(s), potentially contributing to glioma patient prognosis and measuring therapy effectiveness.

Acknowledgments We would like to thank the National Library of Medicine for creating GEO datasets within the public domain and giving users the privilege to freely distribute and copy. In addition to the references from the REMBRANDT database, also considered as public domain, we also are thankful for the GMDI study and REMBRANDT databases. We would like to express our gratitude to the TCGA for providing raw data for analysis. Furthermore, we are deeply grateful to the original contributors who uploaded their data to NIH- and NCI-maintained databases for public use. Special thanks are also given to Human Protein Atlas for their data usage policy, which allows the use of its data and images for noncommercial purposes. Finally, we give our thanks to Dr. Joanna S. O'Leary for technical support in editing this manuscript.

\section{Compliance with Ethical Standards}

Funding J.-J.Z. and M.L. received funding support from Dr. Marnie Rose Foundation and J.T.C from NIH TL1TR000371.

Conflict of Interest None.

Open Access This article is distributed under the terms of the Creative Commons Attribution 4.0 International License (http:// creativecommons.org/licenses/by/4.0/), which permits unrestricted use, distribution, and reproduction in any medium, provided you give appropriate credit to the original author(s) and the source, provide a link to the Creative Commons license, and indicate if changes were made. 


\section{References}

1. Okamoto Y, Di Patre PL, Burkhard C, Horstmann S, Jourde B, Fahey M, Schuler D, Probst-Hensch NM et al (2004) Populationbased study on incidence, survival rates, and genetic alterations of low-grade diffuse astrocytomas and oligodendrogliomas. Acta Neuropathol 108:49-56

2. Benes V 3rd, Barsa P, Benes V Jr, Suchomel P (2009) Prognostic factors in intramedullary astrocytomas: a literature review. Eur Spine J 18:1397-1422

3. Figarella-Branger D, Labrousse F, Mohktari K, Societe Francaise de n. and Reseau de Neuro-Oncologie P (2012) Guidelines for adult diffuse gliomas WHO grade II, III and IV: pathology and biology. Societe francaise de neuropathologie. Reseau de neuro-oncologie pathologique. Ann Pathol 32:318-327

4. Wick W, Weller M, van den Bent M, Sanson M, Weiler M, von Deimling A, Plass C, Hegi M et al (2014) MGMT testing-the challenges for biomarker-based glioma treatment. Nat Rev Neurol 10:372-385

5. Zinn PO, Colen RR, Kasper EM, Burkhardt JK (2013) Extent of resection and radiotherapy in GBM: a 1973 to 2007 surveillance, epidemiology and end results analysis of 21,783 patients. Int $\mathrm{J}$ Oncol 42:929-934

6. Mischel PS, Cloughesy TF, Nelson SF (2004) DNA-microarray analysis of brain cancer: molecular classification for therapy. Nat Rev Neurosci 5:782-792

7. Gorovets D, Kannan K, Shen R, Kastenhuber ER, Islamdoust N, Campos C, Pentsova E, Heguy A et al (2012) IDH mutation and neuroglial developmental features define clinically distinct subclasses of lower grade diffuse astrocytic glioma. Clin Cancer Res 18:2490-2501

8. Figarella-Branger D, Maues de Paula A, Colin C, Bouvier C (2011) Histomolecular classification of adult diffuse gliomas: the diagnostic value of immunohistochemical markers. Rev Neurol 167:683-690

9. Zhang J, Wu G, Miller CP, Tatevossian RG, Dalton JD, Tang B, Orisme W, Punchihewa C et al (2013) Whole-genome sequencing identifies genetic alterations in pediatric low-grade gliomas. Nat Genet 45:602-612

10. Verhaak RG, Hoadley KA, Purdom E, Wang V, Qi Y, Wilkerson MD, Miller CR, Ding L et al (2010) Integrated genomic analysis identifies clinically relevant subtypes of glioblastoma characterized by abnormalities in PDGFRA, IDH1, EGFR, and NF1. Cancer Cell 17:98-110

11. Phillips HS, Kharbanda S, Chen R, Forrest WF, Soriano RH, Wu TD, Misra A, Nigro JM et al (2006) Molecular subclasses of high-grade glioma predict prognosis, delineate a pattern of disease progression, and resemble stages in neurogenesis. Cancer Cell 9:157-173

12. Freije WA, Castro-Vargas FE, Fang Z, Horvath S, Cloughesy T, Liau LM, Mischel PS, Nelson SF (2004) Gene expression profiling of gliomas strongly predicts survival. Cancer Res 64:6503-6510

13. Yan W, Zhang W, You G, Zhang J, Han L, Bao Z, Wang Y, Liu Y et al (2012) Molecular classification of gliomas based on whole genome gene expression: a systematic report of 225 samples from the Chinese Glioma Cooperative Group. Neuro-Oncology 14: $1432-1440$

14. Sekerkova G, Watanabe M, Martina M, Mugnaini E (2014) Differential distribution of phospholipase $\mathrm{C}$ beta isoforms and diaglycerol kinase-beta in rodents cerebella corroborates the division of unipolar brush cells into two major subtypes. Brain Struct Funct 219:719-749

15. Montana M, Garcia del Cano G, Lopez de Jesus M, GonzalezBurguera I, Echeazarra L, Barrondo S, Salles J (2012) Cellular neurochemical characterization and subcellular localization of phospholipase $\mathrm{C}$ beta1 in rat brain. Neuroscience 222:239-268
16. Fukaya M, Uchigashima M, Nomura S, Hasegawa Y, Kikuchi H, Watanabe M (2008) Predominant expression of phospholipase Cbeta1 in telencephalic principal neurons and cerebellar interneurons, and its close association with related signaling molecules in somatodendritic neuronal elements. Eur J Neurosci 28:1744-1759

17. Ross CA, MacCumber MW, Glatt CE, Snyder SH (1989) Brain phospholipase $\mathrm{C}$ isozymes: differential mRNA localizations by in situ hybridization. Proc Natl Acad Sci U S A 86:2923-2927

18. Hannan AJ, Blakemore C, Katsnelson A, Vitalis T, Huber KM, Bear M, Roder J, Kim D et al (2001) PLC-beta1, activated via mGluRs, mediates activity-dependent differentiation in cerebral cortex. Nat Neurosci 4:282-288

19. Hannan AJ, Kind PC, Blakemore C (1998) Phospholipase C-beta1 expression correlates with neuronal differentiation and synaptic plasticity in rat somatosensory cortex. Neuropharmacology 37:593-605

20. Mizuguchi M, Yamada M, Kim SU, Rhee SG (1991) Phospholipase $\mathrm{C}$ isozymes in neurons and glial cells in culture: an immunocytochemical and immunochemical study. Brain Res 548:35-40

21. Lo Vasco VR, Fabrizi C, Artico M, Cocco L, Billi AM, Fumagalli L, Manzoli FA (2007) Expression of phosphoinositide-specific phospholipase $\mathrm{C}$ isoenzymes in cultured astrocytes. J Cell Biochem 100:952-959

22. Lo Vasco VR, Fabrizi C, Fumagalli L, Cocco L (2010) Expression of phosphoinositide-specific phospholipase $\mathrm{C}$ isoenzymes in cultured astrocytes activated after stimulation with lipopolysaccharide. J Cell Biochem 109:1006-1012

23. Bahk YY, Song H, Baek SH, Park BY, Kim H, Ryu SH, Suh PG (1998) Localization of two forms of phospholipase C-beta1, a and b, in C6Bu-1 cells. Biochim Biophys Acta 1389:76-80

24. McLendon R, Friedman A, Bigner D, Van Meir EG, Brat DJ, Mastrogianakis GM, Olson JJ, Mikkelsen T et al (2008) Comprehensive genomic characterization defines human glioblastoma genes and core pathways. Nature 455:1061-1068

25. Costa BM, Smith JS, Chen Y, Chen J, Phillips HS, Aldape KD, Zardo G, Nigro J et al (2010) Reversing HOXA9 oncogene activation by PI3K inhibition: epigenetic mechanism and prognostic significance in human glioblastoma. Cancer Res 70:453-462

26. Sun L, Hui AM, Su Q, Vortmeyer A, Kotliarov Y, Pastorino S, Passaniti A, Menon J et al (2006) Neuronal and glioma-derived stem cell factor induces angiogenesis within the brain. Cancer Cell 9:287-300

27. Khatua S, Peterson KM, Brown KM, Lawlor C, Santi MR, LaFleur B, Dressman D, Stephan DA et al (2003) Overexpression of the EGFR/FKBP12/HIF-2alpha pathway identified in childhood astrocytomas by angiogenesis gene profiling. Cancer Res 63:1865-1870

28. Marron JS, Todd MJ, Ahn J (2007) Distance-weighted discrimination. J Am Stat Assoc 102:1267-1271

29. Machin D, Cheung YB, Parmar M (2006) Survival analysis: a practical approach, 2nd Edn. John Wiley \& Sons, Ltd, Chichester

30. Ostrom QT, Bauchet L, Davis FG, Deltour I, Fisher JL, Langer CE, Pekmezci M, Schwartzbaum JA et al (2014) The epidemiology of glioma in adults: a "state of the science" review. Neuro Oncol 16(7):896-913

31. Wang XW, Boisselier B, Rossetto M, Marie Y, Idbaih A, Mokhtari K, Gousias K, Hoang-Xuan K et al (2013) Prognostic impact of the isocitrate dehydrogenase 1 single-nucleotide polymorphism rs11554137 in malignant gliomas. Cancer 119:806-813

32. Theeler BJ, Yung WK, Fuller GN, De Groot JF (2012) Moving toward molecular classification of diffuse gliomas in adults. Neurology 79:1917-1926

33. Pal S, Bi Y, Macyszyn L, Showe LC, O'Rourke DM, Davuluri RV (2014) Isoform-level gene signature improves prognostic stratification and accurately classifies glioblastoma subtypes. Nucleic Acids Res 42:e64

34. Siegal T (2015) Clinical impact of molecular biomarkers in gliomas. J Clin Neurosci 22:437-444 
35. Mazaris P, Hong X, Altshuler D, Schultz L, Poisson LM, Jain R, Mikkelsen T, Rosenblum M et al (2014) Key determinants of shortterm and long-term glioblastoma survival: a 14-year retrospective study of patients from the Hermelin Brain Tumor Center at Henry Ford Hospital. Clin Neurol Neurosurg 120:103-112

36. Reifenberger G, Weber RG, Riehmer V, Kaulich K, Willscher E, Wirth H, Gietzelt J, Hentschel B et al (2014) Molecular characterization of long-term survivors of glioblastoma using genome- and transcriptome-wide profiling. Int J Cancer 135:1822-1831

37. Watanabe M, Nakamura M, Sato K, Kano M, Simon MI, Inoue $Y$ (1998) Patterns of expression for the mRNA corresponding to the four isoforms of phospholipase Cbeta in mouse brain. Eur $\mathbf{J}$ Neurosci 10:2016-2025

38. Kim D, Jun KS, Lee SB, Kang NG, Min DS, Kim YH, Ryu SH, Suh PG et al (1997) Phospholipase C isozymes selectively couple to specific neurotransmitter receptors. Nature 389:290-293

39. Ruiz de Azua I, del Olmo E, Pazos A, Salles J (2006) Transmembrane signaling through phospholipase C-beta in the developing human prefrontal cortex. J Neurosci Res 84:13-26

40. Laxton RC, Popov S, Doey L, Jury A, Bhangoo R, Gullan R, Chandler C, Brazil L et al (2013) Primary glioblastoma with oligodendroglial differentiation has better clinical outcome but no difference in common biological markers compared with other types of glioblastoma. Neuro-Oncology 15:1635-1643

41. Kurian MA, Meyer E, Vassallo G, Morgan NV, Prakash N, Pasha S, Hai NA, Shuib S et al (2010) Phospholipase C beta 1 deficiency is associated with early-onset epileptic encephalopathy. Brain 133: 2964-2970

42. Ngoh A, McTague A, Wentzensen IM, Meyer E, Applegate C, Kossoff EH, Batista DA, Wang T et al (2014) Severe infantile epileptic encephalopathy due to mutations in PLCB1: expansion of the genotypic and phenotypic disease spectrum. Dev Med Child Neurol 56(11):1124-1128

43. Waugh MG (2014) Chromosomal instability and phosphoinositide pathway gene signatures in glioblastoma multiforme. Mol Neurobiol 10(1):17-25

44. Uhlen M, Oksvold P, Fagerberg L, Lundberg E, Jonasson K, Forsberg M, Zwahlen M, Kampf C et al (2010) Towards a knowledge-based Human Protein Atlas. Nat Biotechnol 28:1248-1250

45. Bahk YY, Lee YH, Lee TG, Seo J, Ryu SH, Suh PG (1994) Two forms of phospholipase C-beta 1 generated by alternative splicing. J Biol Chem 269:8240-8245

46. Matteucci A, Faenza I, Gilmour RS, Manzoli L, Billi AM, Peruzzi D, Bavelloni A, Rhee SG et al (1998) Nuclear but not cytoplasmic phospholipase $\mathrm{C}$ beta 1 inhibits differentiation of erythroleukemia cells. Cancer Res 58:5057-5060

47. García del Caño G, Aretxabala X, González-Burguera I, Montaña M, López de Jesús M, Barrondo S, Barrio RJ, Sampedro C et al (2014) Nuclear diacylglycerol lipase- $\alpha$ in rat brain cortical neurons: evidence of 2-arachidonoylglycerol production in concert with phospholipase C- $\beta$ activity. J Neurochem 57(15):6610-6622

48. Aisiku OR, Runnels LW, Scarlata S (2010) Identification of a novel binding partner of phospholipase cbeta1: translin-associated factor X. PLoS ONE [Electron Resour] 5:e15001

49. Follo MY, Faenza I, Piazzi M, Blalock WL, Manzoli L, McCubrey JA, Cocco L (2014) Nuclear PI-PLC $\beta 1$ : an appraisal on targets and pathology. Adv Biol Regul 54:2-11

50. Follo MY, Finelli C, Bosi C, Martinelli G, Mongiorgi S, Baccarani M, Manzoli L, Blalock WL et al (2008) PI-PLCbeta-1 and activated Akt levels are linked to azacitidine responsiveness in high-risk myelodysplastic syndromes. Leukemia 22:198-200

51. Cocco L, Manzoli L, Palka G, Martelli AM (2005) Nuclear phospholipase $\mathrm{C}$ beta1, regulation of the cell cycle and progression of acute myeloid leukemia. Adv Enzyme Regul 45:126-135

52. Iwakura Y, Nawa H (2013) ErbB1-4-dependent EGF/neuregulin signals and their cross talk in the central nervous system: pathological implications in schizophrenia and Parkinson's disease. Front Cell Neurosci 7:328

53. Follo MY, Manzoli L, Poli A, McCubrey JA, Cocco L (2015) PLC and PI3K/Akt/mTOR signalling in disease and cancer. Adv Biol Regul 57:10-16

54. Piazzi M, Blalock WL, Bavelloni A, Faenza I, Raffini M, Tagliavini F, Manzoli L, Cocco L (2015) PI-PLCbetalb affects Akt activation, cyclin E expression, and caspase cleavage, promoting cell survival in pro-B-lymphoblastic cells exposed to oxidative stress. FASEB J 29:1383-1394

55. Sardi SP, Murtie J, Koirala S, Patten BA, Corfas G (2006) Presenilindependent ErbB4 nuclear signaling regulates the timing of astrogenesis in the developing brain. Cell 127:185-197

56. Abe Y, Namba H, Zheng Y, Nawa H (2009) In situ hybridization reveals developmental regulation of ErbB1-4 mRNA expression in mouse midbrain: implication of ErbB receptors for dopaminergic neurons. Neuroscience 161:95-110

57. Vullhorst D, Neddens J, Karavanova I, Tricoire L, Petralia RS, McBain CJ, Buonanno A (2009) Selective expression of ErbB4 in interneurons, but not pyramidal cells, of the rodent hippocampus. J Neurosci 29:12255-12264 